\title{
$\alpha$-Aminoadipyl-cysteinyl-valine Synthetases
}

\section{in $\beta$-Lactam Producing Organisms}

\section{From Abraham's Discoveries to Novel Concepts of Non-Ribosomal Peptide Synthesis}

\author{
JUAN F. MARTIN \\ Area of Microbiology, Faculty of Biology, University of León, 24071 León, and \\ Institute of Biotechnology, INBIOTEC, Science Park of León, \\ Avda. del Real, $n^{\circ}$ 1, 24006 León, Spain \\ (Received for publication July 27, 2000)
}

\begin{abstract}
The tripeptide $\delta$-(L- $\alpha$-aminoadipyl)-L-cysteinyl-D-valine (ACV) was discovered by ARNSTEIN and MORRIS in Penicillium chrysogenum and ABRAHAM and coworkers in Acremonium chrysogenum. Other analogous tripeptides and tetrapeptides were later reported in these and other $\beta$-lactam producing fungi and actinomycetes. The ACV tripeptide is synthesized by a large non-ribosomal peptide synthetase named ACV synthetase encoded by the $11 \mathrm{~kb}$ $p c b \mathrm{AB}$ gene. This gene has been cloned from the DNA of four different filamentous fungi and two actinomycetes. Detailed analysis of the multifunctional ACV synthetases reveals that they consist of three repeated modules (initially named domains) involved in activation of the corresponding amino acids L- $\alpha$-aminoadipic acid, L-cysteine and L-valine. Each module consists of functional domains for amino acid activation (A), condensation (C) and thiolation (T). In addition the last module of the ACV synthetase contains an epimerization domain (E) involved in conversion of the L-valine to its D-isomer when the tripeptide is still enzyme linked. There are seven epimerization motifs conserved in the third module of all ACV synthetases. In addition, there is an integrated thioesterase domain in the $C$-terminal region of the $\mathrm{ACV}$ synthetases that appears to be involved in the selective release of the tripeptide with the correct LLD configuration. The structure of the ACV synthetase is similar to that of other modular non-ribosomal peptide synthetases of bacterial and fungal origin. This molecular knowledge opens the way for engineering novel tripeptide synthetases that may result in new bioactive compounds.
\end{abstract}

ABRAHAM and coworkers at Oxford were the first to establish solid basis to understand the biosynthesis of $\beta$-lactam antibiotics in fungi ${ }^{1,2}$. They elucidated the role of the tripeptide $\alpha$-aminoadipyl-cysteinyl-valine (ACV) discovered initially by ARNSTEIN and MORRIS ${ }^{3)}$ in the biosynthesis of $\beta$-lactams ${ }^{4,5)}$.

Following initial studies on precursor incorporation into penicillin, ARNSTEIN and coworkers observed the formation of the tripeptide $\mathrm{ACV}^{3,6)}$. This tripeptide was shown to have the configuration $\delta$-(L- $\alpha$-aminoadipyl-L-cysteinyl-Dvaline $^{7}$.

\section{Peptides Analogous to $\mathrm{ACV}$}

Soon after the discovery of the ACV tripeptide (named

Dedicated to the memory of Sir EDWARD ABRAHAM. 
P1) other analogous peptides were found in $P$. chrysogenum, Cephalosporium acremonium (renamed Acremonium chrysogenum) and Paecilomyces persicinus. Neuss and coworkers ${ }^{8)}$ described three other peptides in P. chrysogenum with the structures:

P2 $\alpha$-aminoadipyl-alanyl-valine

P3 $\alpha$-aminoadipyl-serinyl-valine

P4 $\alpha$-aminoadipyl-serinyl-isodehydrovaline

The formation of these peptides may be explained on the basis of the low substrate specificity of the non-ribosomal peptide synthetase although post-synthetic modifications of some amino acids by "tailoring" enzymes can not be excluded (see below). Later, AvANZINI and coworkers $\left.{ }^{9}, 10\right)$ reported the presence of a peptide formed by $\alpha$-aminoadipic and valine but not cysteine in several strains of $P$. chrysogenum. It is unclear how this dipeptide may be formed; the authors suggested that it may be synthesized by a different enzyme system following the release of $\alpha$ aminoadipic acid from isopenicillin $\mathrm{N}$ after cleavage by the isopenicillin $\mathrm{N}$ acyltransferase.

A mixture of ACV related peptides was found in the mycelium of Acremonium chrysogenum. The major component (A1) of the mixture was identified as $\mathrm{ACV}^{11,12)}$ but two minor components were tetrapeptides, one (A2) containing $\alpha$-aminoadipic acid, cysteine, valine and glycine and the second one (A3) containing a $\beta$-hydroxyvaline residue in place of valine ${ }^{11,12)}$.

Later ENRIQUeZ and PISANO ${ }^{13}$ identified two tetrapeptides in addition to the standard tripeptide in the cephalosporin producer Paecilomyces persicinus (PP peptides).

PP1 $\delta$-( $\alpha$-aminoadipyl)-cysteinyl-valine

PP2 Glycyl- $\delta$-( $\alpha$-aminoadipyl)-cysteinyl$\beta$-hydroxyvaline

PP3 Glycyl- $\delta$-( $\alpha$-aminoadipyl)-cysteinyl-valine

The $P$. persicinus peptides seem to be identical to those of $A$. chrysogenum. The PP1 tripeptide corresponds to the ACV tripeptide and the PP2 and PP3 tetrapeptides appear to be identical to the $\mathrm{A} 3$ and $\mathrm{A} 2$ peptides of $A$. chrysogenum, respectively, although the exact sequence of amino acids in the $A$. chrysogenum tetrapeptides have not been reported. ENRIQUEZ and PISANO ${ }^{13)}$ proposed that glycyl-ACV may be the real precursor for cephalosporin biosynthesis but this hypothesis has not been substantiated further.

It is interesting that a significant proportion of the $\mathrm{ACV}$ tripeptide is secreted to the culture broth. This observation was made initially by ADRIAENS et al. ${ }^{14)}$ and confirmed in our laboratory using P. chrysogenum strains of low and high penicillin producing ability ${ }^{15)}$. Since the ACV tripeptide is not taken back into the cytoplasm ${ }^{(4)}$, the role of the tripeptide in the broth is probably not related to penicillin biosynthesis and it may serve as chemical signals for intercellular communication (pheromones).

\section{II. $\alpha$-Aminoadipyl-cysteinyl-valine Synthetase: The First Enzyme of the $\beta$-Lactam Biosynthetic Pathway}

Penicillins, cephalosporins and cephamycins are $\beta$ lactam antibiotics formed by condensation of $\mathrm{L}-\alpha-$ aminoadipic acid (an intermediate of the lysine biosynthetic pathway in fungi), L-cysteine and L-valine. The three L-amino acids are activated and linked together to form the tripeptide $\delta$-(L- $\alpha$-aminoadipyl)-L-cysteinyl-D-valine. The L-valine molecule is epimerized to the D-configuration during formation of the tripeptide (Fig. 1). Biosynthesis of the ACV tripeptide was initially thought to proceed in two steps forming first the dipeptide $\mathrm{AC}$ and then the tripeptide $A C V^{16)}$. This led to the proposal of two loci $p c b \mathrm{~A}$ and $p c b \mathrm{~B}$ for the putative genes encoding these enzymes ${ }^{17}$.

Later evidence indicated that formation of the $\mathrm{ACV}$ tripeptide is catalyzed by a single enzyme named $\mathrm{ACV}$ synthetase, which requires ATP (i.e. it is a true synthetase) and $\mathrm{Mg}^{2+}$ ions ${ }^{18,19)}$. Since formation of ACV is the first step committing the amino acids to the $\beta$-lactam biosynthetic pathway, the role of ACV synthetase is of great interest. Recently it has been reported that ACV synthetase activity is limiting for penicillin biosynthesis in wild type Aspergillus nidulans strains ${ }^{20)}$.

Cell-free systems catalyzing ACV synthesis were first described using extracts of $A$. chrysogenum ${ }^{21,22)}$ and $S$. clavuligerus $^{23)}$. The multifunctional ACV synthetase was purified from Aspergillus nidulans ${ }^{24)}$, A. chrysogenum ${ }^{21,25)}$ and $S$. clavuligerus ${ }^{23,25,26)}$. The molecular weight of the $A$. nidulans enzyme was originally reported to be $220 \mathrm{kDa}$, but recent data based on analysis of the cloned gene indicates that its molecular weight is about $400 \mathrm{kDa}$. For the $A$. chrysogenum enzyme ZHANG and DEMAIN reported that the native enzyme is a dimer of about $800 \mathrm{kDa}$ composed of two identical subunits ${ }^{21}$. The $S$. clavuligerus $\mathrm{ACV}$ synthetase appears to be a monomer of about 350 to $400 \mathrm{kDa}^{23)}$ although these values do not agree with those reported by JENSEN ${ }^{26)}$ and BALDWIN ${ }^{25)}$. The discrepancies appear to be due to the lack of appropriate size markers for the SDS-PAGE of these large proteins.

The tripeptide $\mathrm{ACV}$ in a second step, is oxidatively 
Fig. 1. Organization of domains of the ACV synthetases and model of elongation of the tripeptide chain. $\alpha$-AAA, cys and val indicate the three repeated modules of the ACV synthetases.
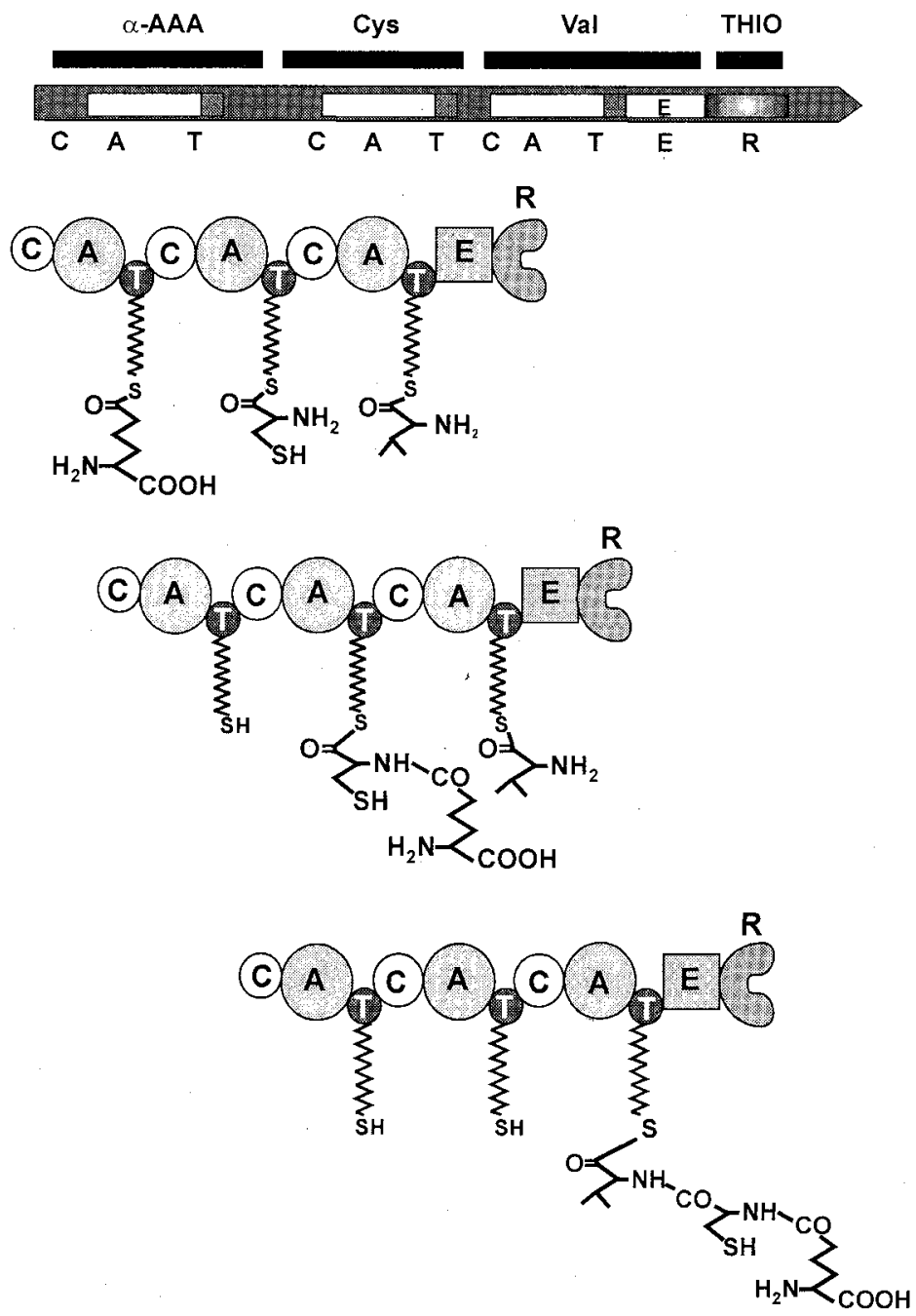

The three classical amino acid activating domains (see text) are now designated as modules and subdivided into functional domains. THIO corresponds to the thioesterase domain downstream of the Val module. A, activation domains; $\mathrm{C}$, condensation domains; $\mathrm{T}$, thiolation domains; $\mathrm{E}$, epimerase domain (occurs only in the valine module); $\mathrm{R}$, Release (thioesterase) domain. Note that elongation of the growing tripeptide chain takes place by activation and transfer of the amino acid to the thiol group of the phosphopantetheine arm linked to the T domain of each module. Epimerization of the L- to the D-valine appears to occur in the tripeptide chain attached to the enzyme (see text).

cyclized by removal of four hydrogen atoms to form the $\beta$-lactam-thiazolidine nucleus of isopenicillin $\mathrm{N}$ which is later converted into penicillins containing phenylacetic acid, phenoxyacetic acid or other hydrophobic side chains [reviewed by DEMAIN ${ }^{5)}$, MARTín and LIRAS ${ }^{27)}$, and Aharonowtiz et al. ${ }^{28)}$ ]. Further "late" modifications convert isopenicillin $\mathrm{N}$ into either cephalosporins or cephamycins $^{29)}$.

\section{Substrate Specificity of the ACV Synthetases}

Studies on the substrate specificity of the ACV synthetases were hampered by the difficulty to obtain pure preparations due to its large size and by its instability ${ }^{12,18,22,30)}$. The ACV synthetases can be partially

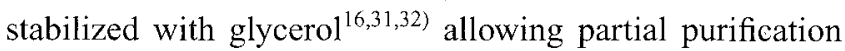
of the enzyme. 
Table 1. In vitro replacement of substrate amino acids by analogues using different ACV synthetases.

\begin{tabular}{|c|c|c|c|}
\hline Source of ACV synthetase & Normal substrates & Other amino acids used as substrates & References \\
\hline \multirow[t]{3}{*}{ A. chrysogenum } & L- $\alpha$-AAA replaced by & $\begin{array}{l}\text { L-S-Carboxymethylcysteine } \\
\text { L-Glutamate (very low activity) }\end{array}$ & 31,35 \\
\hline & L-Cysteine & $\begin{array}{l}\text { L-Allylglycine } \\
\text { L-Vinylglycine } \\
\text { DL- } O \text {-Methylserine } \\
\text { L-S-Methylcysteine }\end{array}$ & 35 \\
\hline & L-Valine & $\begin{array}{l}\text { L-allo-Isoleucine } \\
\text { L- } \alpha \text {-Aminobutyrate }\end{array}$ & 31,35 \\
\hline \multirow[t]{3}{*}{ S. clavuligerus } & $\mathrm{L}-\alpha-\mathrm{AAA}$ & L-S-Carboxymethylcysteine & 33,34 \\
\hline & L-Valine & $\begin{array}{l}\text { L-allo-Isoleucine } \\
\text { L- } \alpha \text {-Aminobutyrate } \\
\text { L-Norvaline } \\
\text { L-Allylglycine }\end{array}$ & 33,34 \\
\hline & L-Cysteine & $\begin{array}{l}\text { L-Homocysteine } \\
\text { S-Methyl-L-cysteine }\end{array}$ & 33,34 \\
\hline A.lactamdurans (formerly $N$. lactamdurans) & $\begin{array}{l}\text { L- } \alpha \text {-Aminoadipic acid } \\
\text { L-Cysteine }\end{array}$ & $\begin{array}{l}\text { 6-Oxopiperioline-2-carboxylic acid } \\
\text { L-Cystathionine }\end{array}$ & 36 \\
\hline
\end{tabular}

The crude ACV synthetase from A. chrysogenum showed some degree of substrate unspecificity. LCarboxymethylcysteine could replace $\mathrm{L}-\alpha$-aminoadipic acid but L-aspartate, adipate or phenylacetate could not. Similarly, L-valine was replaced by L-allo-isoleucine and $\alpha$-aminobutyrate but not by D-valine, L-isoleucine or glycine (Table 1). Similar results on substrate specificity were observed with the $\mathrm{ACV}$ synthetase of $S$. clavuligerus $^{33,34)}$ (Table 1).

This relative lack of substrate specificity of the ACV synthetase was later confirmed by BALDWIN and co-workers ${ }^{35)}$. Using the $A$. chrysogenum enzyme, these authors found that the $S$-carboxymethylcysteine was an effective substitute for $\alpha$-aminoadipate and both allylglycine and vinylglycine could substitute for cysteine showing that the thiol group of cysteine is not essential for peptide formation. Similarly, L-alloisoleucine but not L-isoleucine substituted effectively for valine. The structure of the alternative peptide products was confirmed by NMR and electrospray-ionization mass spectrometry.

Similarly, the purified ACV synthetase of Nocardia lactamdurans can use 6-oxopiperidine 2-carboxylic acid (cyclic form of $\alpha$-aminoadipic acid) or cystathionine in place of $\alpha$-aminoadipic acid or cysteine, respectively ${ }^{36}$.

\section{The pcbAB Gene Encodes ACV Synthetase}

The $P$. chrysogenum $p c b \mathrm{AB}$ gene that encodes $\mathrm{ACV}$ synthetase was first cloned by DíEz et al. ${ }^{37)}$ and simultaneously by TURNER and coworkers ${ }^{38}$. Both groups provided evidence showing that the $p c b \mathrm{AB}$ is an unusually large gene (11,376 nucleotides) encoding a protein of 3,792 amino acids with a deduced molecular mass of 425,971 . The cloned $p c b \mathrm{AB}$ gene complements a non-producer mutant $P$. chrysogenum npe5 defective in ACV synthetase $^{399}$.

Soon after the $P$. chrysogenum $p c b \mathrm{AB}$ gene was reported, the $p c b \mathrm{AB}$ of Acremonium chrysogenum was also cloned by hybridization with probes internal to the Penicillium gene ${ }^{40)}$. A $15.6 \mathrm{~kb}$ DNA fragment was shown to complement the $P$. chrysogenum npes mutant that is defective in ACV synthetase. The A. chrysogenum pcbAB gene contained 11,136 nt encoding a protein of 3,712 amino acids with a deduced molecular weight of 414,791 Da. Similarly, the ACV synthetase gene of A. nidulans (named $a c v A$ ) was cloned by MCCABE $e t a l .{ }^{41)}$ and MONTENEGRO et $a l .{ }^{42)}$. The $p c b \mathrm{AB}$ has also been found recently in Penicillium nalgiovense $^{43)}$ (Laich, F. \& J. F. Martín, 
unpublished data).

Genes encoding ACV synthetases were also cloned from the cephamycin producing actinomycetes $N$. lactamdurans ${ }^{44)}$ (recently renamed Amycolatopsis lactamdurans) $)^{45)}$ and $S$. clavuligerus ${ }^{46,47)}$. The $A$. lactamdurans pcbAB gene encodes a protein of 3,694 amino acid with a molecular weight of 404,134 Da. In $S$. clavuligerus the sequence of only a 712 bp of the 3 ' end of the $\mathrm{ORF}$ is $\mathrm{known}^{46)}$. In all fungi the $p c b \mathrm{AB}$ gene is expressed in opposite orientation to the $p c b \mathrm{C}$ gene (encoding isopenicillin $\mathrm{N}$ synthase), the second gene of the penicillin and cephalosporin pathway whereas in bacteria the $p c b \mathrm{AB}$ gene is arranged in the same orientation as the $p c b \mathrm{C}$ gene $^{44)}$.

In spite of its large size, the fungal $p c b \mathrm{AB}$ genes lack introns. The lack of introns suggests that the ACV synthetase gene is of bacterial origin and it has been transferred horizontally to filamentous fungi ${ }^{28)}$. Both the fungal and bacterial genes share a high degree of homology. The three fungal $p c b \mathrm{AB}$ genes are $71 \%$ identical, whereas the bacterial genes show about $48 \%$ identical amino acids with the fungal genes. Since the similarity between fungal and bacterial $p c b \mathrm{AB}$ genes is much higher than that expected on the basis of the separate evolution of procaryotic and eucaryotic microorganisms, this similarity further supports the hypothesis of the horizontal transfer of these genes in soil ${ }^{28,48,49)}$

\section{Involvement of the pcbAB Gene in $\beta$-Lactam Biosynthesis: Evidence for a Single Copy of This Gene}

The involvement of the $p c b \mathrm{AB}$ gene in penicillin biosynthesis was established by gene disruption studies. Disruption of the $p c b \mathrm{AB}$ gene of $A$. chrysogenum ${ }^{50)}$ and $A$. nidulans $^{38)}$ led to the loss of $\mathrm{ACV}$ synthetase and cephalosporin or penicillin production ability, respectively. These results unequivocally indicate that formation of $\mathrm{ACV}$ is required for penicillin or cephalosporin biosynthesis. Hybridization studies of total DNA of $P$. chrysogenum and $A$. chrysogenum with probes internal to the $p c b \mathrm{AB}$ gene indicated that there is a single set of the penicillin ${ }^{51)}$ or cephalosporin (GUTIÉRREZ, S. \& J. F. MARTíN, unpublished) gene cluster in wild type strains of these fungi. High penicillin producing strains contain multiple copies of the $p c b \mathrm{AB}-p c b \mathrm{C}-p e n \mathrm{DE}$ cluster reiterated in tandem ${ }^{52)}$.

\section{Are the Cephalosporin Tetrapeptides Formed by the ACV Synthetase?}

$\alpha$-Aminoadipic acid-containing tetrapeptides are synthesized in $A$. chrysogenum and $P$. persicinus but not in $P$. chrysogenum. It is unclear if the tetrapeptides are synthesized by the ACV synthetase itself although it seems unlikely since the tripeptide synthetase only contains three amino acid-activating modules. No studies have been performed on the presence or absence of the tetrapeptides in $A$. chrysogenum mutants disrupted in the $p c b \mathrm{AB}$ gene.

Hybridization studies excluded the possibility of a second peptide synthetase (forming the $\alpha$-aminoadipic acid containing tetrapeptides) similar to the ACV synthetase since a single hybridizing band was observed in hybridizations of total DNA with a probe internal to the $p c b \mathrm{AB}$ gene. A possible explanation is that the tetrapeptides are formed by a glycine activating singlemodule enzyme that might be able to transfer the activated glycine into the ACV tripeptide formed by the ACV synthetase.

\section{Domains in Peptide Synthetases}

The non-ribosomal peptide synthases constitute a group of biosynthetic enzymes of great interest because they catalyze a novel route of peptide bond formation independent of ribosomes ${ }^{53 \sim 56)}$.

Domains similar to those of the ACV synthetase have been found in a large number of enzymes that activate their substrate amino acids as aminoacyl-adenylates, and bind the amino acids covalently as thioesters (Fig. 2). This group includes all peptide synthetases of diverse origins. A region homologous to the repeated domains of ACV synthetases was also found in enzymes not involved in peptide synthesis that activate their substrates with ATP including among others i) the $\alpha$-aminoadipate reductase (LYS2 gene) of Saccharomyces cerevisiae, $P$. chrysogenum ${ }^{57)}$ and $A$. chrysogenum $^{58)}$ which activates $\alpha$-aminoadipate with ATP for reduction to the $\alpha$-aminoadipic semialdehyde, ii) the EntE protein involved in enterobactin synthesis in $E$. coli, which activate 2,3-dihydroxybenzoate, iii) the acetyl-CoA synthetases of $A$. nidulans and Neurospora crassa and iv) the 4-coumaryl-CoA ligase of parsley and the $p$ aminobenzoyl-CoA ligase of $S$. griseus involved in candicidin biosynthesis ${ }^{59)}$. These acyl-activating enzymes have a conserved domain of about 550 amino acids (shorter than the 1,000 amino acid domains of peptide synthetases) 
Fig. 2. Conserved motifs in the modules of acyl-adenylating enzymes (type A), $\alpha$-aminoadipate reductase of the lysine pathway (type L) and non-ribosomal peptide synthetases (type B1, B2 and M).

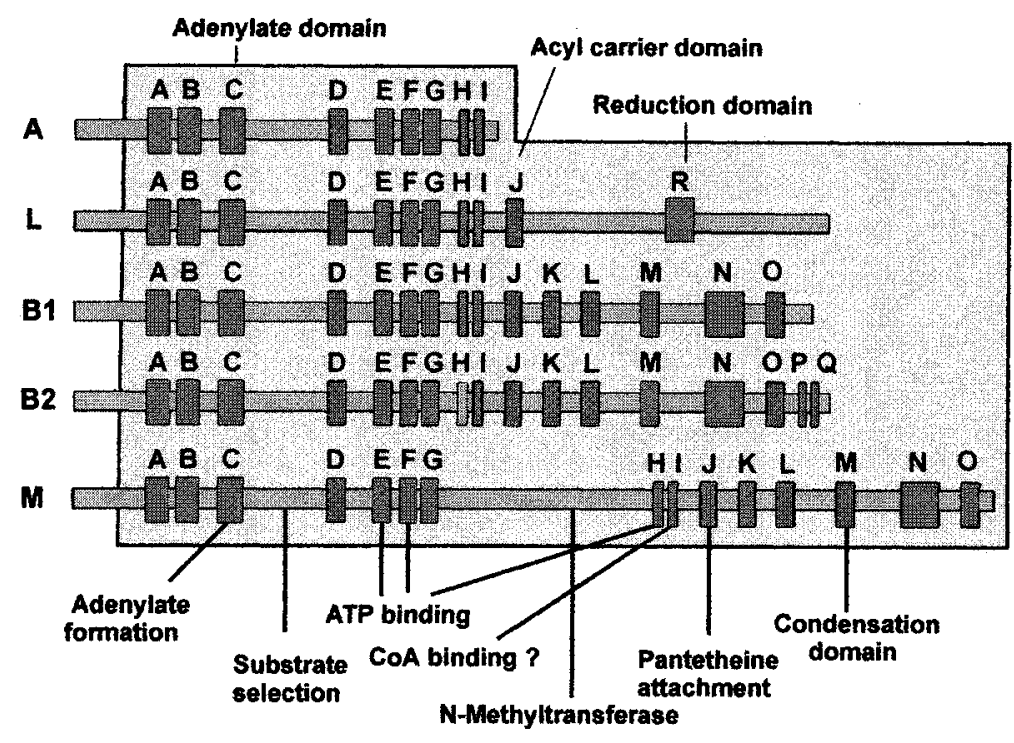

\begin{tabular}{|l|l|}
\hline Adenylation & A: L(T/S)YXEL \\
& B: LKAGXAYL(VIL)P(L/I)D \\
C: LAYXXYTSG(S/T)TGXPKGFDXS & D: IVNXYGPTE \\
& E: GELXIXGXG(V/L)ARGYL \\
& F:Y(R/K)TGDL \\
G: GRXDXQVKIRGXRIELGEIE & H: LPXYM(IV)P \\
& I: NGK(V/L)DR \\
Thiolation & J: DXFFXXLGG(H/D)S(L/I) \\
Thioesterase| Thio: G(H/Y)SXG
\end{tabular}

B2 modules are longer than B1 and contain epimerization motifs. Type $M$ modules contain a $50 \mathrm{kDa}$ methyltransferase domain inserted between motifs $\mathrm{G}$ and $\mathrm{H}$ (see text).

\section{(Fig. 2).}

All these enzymes have in common their ability to activate the carboxyl group of the corresponding substrate through formation of acyladenylates. MARAHIEL and coworkers have proposed the designation of the adenylateforming enzyme superfamily for this group of enzymes ${ }^{60 \sim 62)}$.

The relationship between peptide-synthetases and acylCoA ligases is intringuing. Peptidyl macrolactones such as rapamycin or FK-506 originate from both carboxylic acids and amino- or imino acids ${ }^{63)}$. Some of the peptide synthetase combine subunits activating amino acids with other that activate organic acid. One of the domains (EA) of enniantin synthetase is involved in activation of the $D$ hydroxyisovaleric (D-HIV) acid which only requires adenylation whereas the EB domains activate the branched chain amino acid (L-valine and L-isoleucine) forming its $N$ methylderivative and catalyze the formation of the peptide bond ${ }^{64)}$.

One interesting finding is that the size of the peptide synthetases is directly proportional to the number of domains, which in turn is identical to the number of amino acids that are activated. Gramicidin synthetase 1 (GS1) and tyrocidine synthetase 1 (TY1) with sizes of 126 and $120 \mathrm{kDa}$ activate a single amino acid; enniantin synthetase which activates two residues has a molecular weight of $347 \mathrm{kDa}$; ACV synthetase and tyrocidine synthetase 2 (TY2) which activate three amino acids have molecular weights of 404 to $425 \mathrm{kDa}$; gramicidin synthetase 2 (GS2) which activates four amino acids shows a molecular weight of $562 \mathrm{kDa}$ and cyclosporin synthetase which activates 11 amino acids has a calculated molecular weight of 
$1689 \mathrm{kDa}^{65)}$.

However not all peptide synthases have all amino acidactivating domains in a single polypeptide. Fungal peptide synthetase are more integrated than their bacterial counterparts. So far, the most complex fungal peptide synthetase is the cyclosporin synthetase that activates 11 amino acids and is a 1.69 million Da protein ${ }^{65)}$. The largest known prokaryotic enzyme is the lysobactin synthetase from Lysobacter sp. that activates and adds 8 amino acids to a tripeptide precursor, and has an estimated size of 1 million $\mathrm{Da}^{66)}$. It is not known why multifunctional peptide synthetases are sometimes encoded by a single gene resulting in a large multimodular protein and sometimes (e.g. lysobactin) are encoded by two genes forming two peptide synthetases that interact between them.

\section{Colinearity Between Peptide Synthetase Modules and the Order of Amino Acids in the Non-ribosomal Peptides}

More and more genes encoding peptide synthetases are being sequenced every year. Initial studies on three tryptic fragments of the gramicidin synthetase GS2 which specifically activate proline, ornithine and leucine established the basis of the colinearity rule. The biochemical evidence available indicates that modules 1,3 and 4 of GS2 activate proline, ornithine and leucine, respectively. The remaining-domain contains the site for valine activation ${ }^{55)}$. These results indicate that there is a functional colinearity between the modules in the GS2 protein as deduced from the nucleotide sequence and the order of the amino acids incorporated into gramicidin $\mathrm{S}$.

The largest peptide synthetase cloned so far, the cyclosporin synthetase, contains 11 modules that also appear to adjust to the principle of functional colinearity ${ }^{65)}$. There are two types of modules in the cyclosporin synthetase. Type I is very similar to the standard modules (about $1000 \mathrm{aa}$ ) found in other multifunctional peptide synthetases. Type II is larger than the first and include a 450 amino acid stretch that corresponds to a region involved in $S$-adenosylmethionine binding as defined experimentally by photoaffinity labeling with $S$ adenosylmethionine after endoproteolytic digestion (Fig. 2 ). There are four type I and seven type II modules in the cyclosporin synthetase. The order of the eleven type I and type II modules (without or with the methyltransferase activity, respectively) corresponds exactly with the order of non-methylated and methylated amino acids in cyclosporin $^{65)}$.
IX. Amino Acid Condensation in ACV: a Revised Mechanism of Peptide Chain Elongation

The thiol template mechanism for the synthesis of ACV postulates that the first condensation step leads to the formation of the peptide bond between the $\delta$-carboxyl of $\mathrm{L}-\alpha$-aminoadipic acid and the amino group of L-cysteine prior to the formation of the bond between L-cysteine and $\mathrm{L}-\mathrm{valine}$. However this mechanism has been disputed by SHIAU and coworkers ${ }^{67,68)}$ who observed that purified preparations of the $\mathrm{ACV}$ synthetase form two diasteroisomeric dipeptides, L-( $O$-methylserinyl $)$-L-valine and $\mathrm{L}-(O$-methylserinyl $)$-D-valine when the enzyme was incubated with $\alpha$-aminoadipate, L-valine and the cysteine analogue $\mathrm{L}-O$-methylserine ${ }^{67)}$. Later the same authors reported the isolation of the dipeptide $\alpha$-cysteinyl-D-valine from incubations of ACV synthetase with L-cysteine and Lvaline. Formation of the L-cysteinyl-D-valine dipeptide was significantly enhanced in the presence of L-glutamate, apparently due to inteference of L-glutamate with the $\alpha$ aminoadipate activation and condensation steps. The efficient formation of the dipeptide L-cysteinyl-D-valine under these conditions suggests that epimerization of the $L$ valine takes place at the enzyme-bound dipeptide stage. SHIAU and coworkers ${ }^{69)}$ concluded that the peptide bond between $\alpha$-aminoadipate and cysteine is formed after the Lcysteine-D-valine is synthesized and that thioesterification of valine is not obligatory for peptide bond formation. They proposed a revised mechanism of peptide chain elongation in which formation of the ACV starts with the condensation of L-cysteine and L-Valine ${ }^{67 \sim 69)}$. This result is consistent with the reported utilization of cystathionine ( $S$-[2-amino2-carboxyethyl]homocysteine) by the ACV synthetase of $N$. lactamdurans to form $\mathrm{ACV}^{36)}$.

\section{Specific Motifs and Structural Organization of the Amino Acid Activating Modules of ACV Synthetases}

When the ACV synthetases were compared with other peptide synthetases, and with other members of the adenylate-forming enzyme superfamily, several highly conserved amino acid sequences were found ${ }^{70)}$. These are named boxes A, B, C, D, E, F, G, H, I and J (Fig. 2). Boxes $A$ to $\mathbf{J}$ correspond to the sequences of greater similarity between all peptide synthetases. Motifs A, C, D, E, F, G, H and $I$ were present in all the acyladenylate-forming enzymes and, therefore, seem to be involved in nucleotide 
Fig. 3. Conserved motifs E1 to E7 in the epimerization domain (E) of the third (Val) module of the ACV synthetases of $P$. chrysogenum, $A$. chrysogenum, $N$. lactamdurans and $A$. nidulans as compared to the GrsA (GSI) and the SrfA modules of B. subtilis and the HC toxin synthetase of $C$. carbonum.

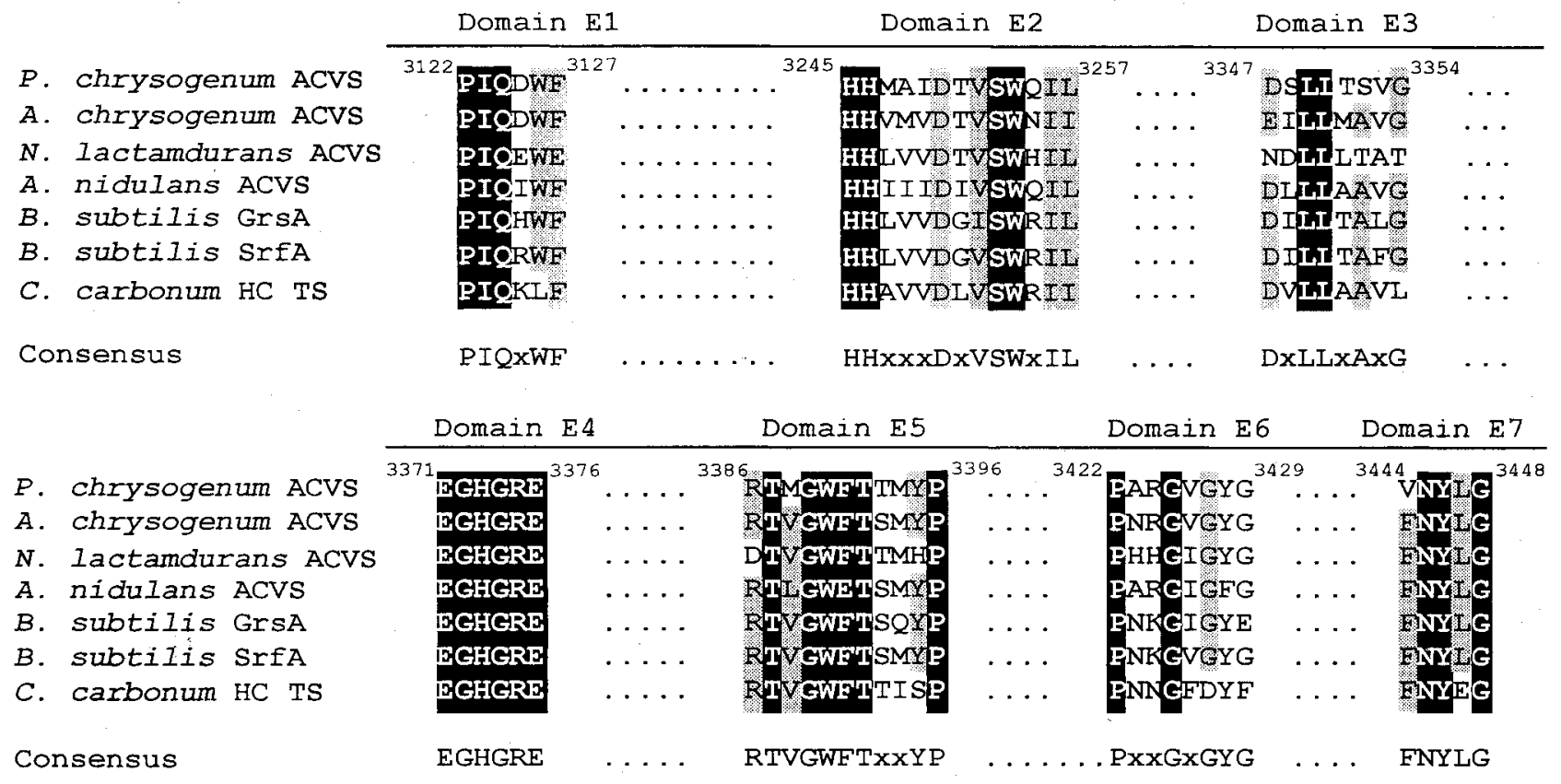

The consensus sequence was proposed by MARAHIEL et al ${ }^{61)}$. Identical amino acids in all microorganisms are in reverse type, and other amino acids conserved with respect to the consensus are shaded. The amino acid numbers (in superscript) correspond to the $P$. chrysogenum $\mathrm{ACV}$ synthetase.

and carboxylic acid binding to form the acyladenylate.

The J-box (initially know as $\mathrm{W}$ box ${ }^{70)}$ is present only in the domains of peptide synthetases and in the $\alpha$ aminoadipate reductase (Lys2) $)^{57,58)}$ but not in other adenylate-forming enzymes that do not form peptide bonds. This J-box corresponds to the sequence of a peptide fragment of GS2 containing covalently attached valine isolated after charging the enzyme with this amino acid. This site may, therefore, correspond to the active center for late stages of activation of the amino acid, i.e. the site of formation of the activated ester from which the peptide bond is made.

Each module of the ACV synthetase corresponds to about 1,000 amino acids. Most of the conserved amino acid sequences are clustered in a 600 amino acid region, but the active fragments of the GS2 that are able to activate proline, leucine and ornithine have molecular weights of $110 \sim 120 \mathrm{kDa}$ that corresponds to $1,000 \sim 1,100$ amino acids. This implies that the regions downstream from the J-box are also important for functionality of the peptide synthetase modules ${ }^{61)}$.

The third module (type B2) of the ACV synthetases
(Fig. 2) is longer than the first two (type B1) and contains two additional conserved boxes. This region corresponds to the epimerization region of the valine module of $\mathrm{ACV}$ synthetases.

Proper characterization of the size and limits of each domain is of extreme interest for peptide synthetase engineering ${ }^{71 \sim 73)}$.

The Aminoacyl-adenylate Forming Region

Many different enzymes that activate their substrates with ATP as aminoacyl-adenylates have been compared. The sequence SG(S/T)TGXPKG (box $\mathrm{C}$ ) resembles the glycine-rich loops involved in ATP-binding. The conserved sequence $\mathrm{Y}(\mathrm{K} / \mathrm{R}) \mathrm{TGDL}$ (so called TGD box or box $\mathrm{F}$ in Fig. 2) is conserved in an extense family of ATPases. This TGD sequence appears to serve as a pocket for binding the ATP nucleotide involved in amino acid activation. In vitro directed mutation of the SGTTGXPKG motif (box C) and the TGD motif of the tyrocidine synthetase resulted in a considerable decrease of enzyme activity, particularly in the mutations altering the lysine of box $\mathrm{C}$ and the aspartic acid of the TGD box, what indicates that these two motifs 
are important for amino acid activation as aminoacyladenylates (regions named A in Fig. 1). Further support for this- hypothesis has been provided by identifying the sequence of a GS2 mutant that is deficient in proline activation. This mutation altered the glycine of the TGD motif of the proline-activating domain. The consensus motifs of adenylation domains serve for identification of novel amino acid-activating domains in sequences deduced from genome analysis ${ }^{74)}$.

Recently, a peptide corresponding to the adenylation domain of gramicidin synthetase 1 overexpressed in $E$. coli has been crystallized and the $3 \mathrm{D}$ structure resolved at the $1.9 \AA^{75,76)}$. The $3 \mathrm{D}$ structure of this domain is similar to the structure of the acyl-CoA-forming luciferase and it is likely that the 3D structure is similar in all aminoacyl- and acyladenylate forming enzymes.

\section{Panthetheine-binding Sequences}

The stability of the peptide synthetase-substrate complexes at acidic $\mathrm{pH}$ but not in alkaline $\mathrm{pH}$ and the rapid hydrolysis with peroxyacids led to the conclusion that the amino acids are activated as thioesters. SchlumBoHm and coworkers $^{77}$ ) identified the valine (or leucine) binding sequences of the GS2 that contained the sequence LGGHS that correspond to the $\mathrm{J}$ box region. This amino acidbinding motif does not contain a cysteine (instead it shows a serine) and there are no conserved cysteines in this region of the peptide synthetases. It seems, therefore, that this sequence binds a thiol-containing phosphopantetheine that may in turn form the thioester with the activated amino acid. This model is very likely to be functional in vivo since pantetheine has been found to be present in $\mathrm{ACV}$ synthetase $^{22)}$ and other peptide synthetases ${ }^{78)}$. Moreover the $\mathrm{LGG}(\mathrm{H} / \mathrm{D}) \mathrm{S}$ motif (box $\mathrm{J}$ ) is present in all the domains of peptide synthetases which are able to form thioester bonds, but it is absent in adenylate-forming enzymes which are unable to form thioesters. The LGG(H/D)S sequence is known to be a consensus motif of phosphopanteheinebinding in the acylcarrier proteins (ACP) of the fatty acid synthetases and in the polyketide synthetases of a variety of secondary metabolites ${ }^{79)}$.

If there is a pantetheine binding site in each domain (i.e. 3 molecules in the ACV synthetases), the content of this vitamin should be higher than previously reported for different $\mathrm{ACV}$ synthetases ( 0.95 to 1 moles per mole of protein) $)^{22)}$.
An Acyl-carrier (Thiolation) Region in Each Peptide Synthetase Module

Alignment of the E. coli acyl-carrier protein with the modules of the ACV synthetases showed that the homology could be extended for $80 \sim 100$ amino acids on both sides of the $J$ box for the entire length of the ACP. The tridimensional structure of the ACP protein of $E$. coli has been determined; it is formed by four $\alpha$-helices connected by turns. The pantetheine binding site (Ser 36) is located in one of the turns that binds two of the central $\alpha$-helices. An analysis of the predicted secondary structure of the three ACV synthetase modules around the LGG(H/D)S motif ( $\mathbf{J}$ box) shows the presence of two amphipatic $\alpha$-helices on both sides of a turn formed by the LGGXS motif. These observations indicate that an "ACP region" or thiolation region ( $\mathrm{T}$ in Fig. 1) is integrated within each module of the peptide synthetases, as occurs also in polyketide synthases $^{80)}$.

An Epimerase Motif at the End of the Third Module of ACV Synthetases

Many non-ribosomally synthesized peptides contain Damino acids ${ }^{53,54,80)}$. The $C$-terminal region of the ACV synthetases of $P$. chrysogenum, $A$. nidulans, $A$. chrysogenum and $A$. lactamdurans located after the end of the third module shows high similarity with the homologous regions of GS1 and TY1 and the third module of the surfactin synthetase 1. Since all those peptide antibiotics contain a D-amino acid in its carboxyl terminal region (D-Phe in gramicidin and tyrocidine; D-leu in surfactin) it was proposed that an epimerization domain of about 365 amino acids is located in this region ${ }^{81,82)}$. Epimerization domains of several non-ribosomal peptide synthetases are now known and all contain characteristic signature sequences. The involvement of a basic amino acid in these motifs as a proton donor/acceptor during racemization of phenylalanine has been proposed ${ }^{82)}$. These motifs have been found in the $\mathrm{V}$ module of ACV synthetases (Fig. 3) and in a HC-toxin synthetase domain epimerizing L-Pro to D-Pro ${ }^{83)}$. It is important to note that the homologous sequences in the $\mathrm{A}$ and $\mathrm{C}$ modules of the ACV synthetase do not adjust or very poorly to the consensus epimerase signatures. Further biochemical analysis of these epimerization motifs are required to confirm that they constitute an authentic catalytic site for amino acid epimerization.

On the other hand, the D-alanine component of cyclosporin is provided by a distinct alanine racemase that may interact with the peptide synthetase ${ }^{84)}$. The HC-toxin producer Cochliobolus carbonum contains an alanine 
racemase involved in the conversion of L- to D-alanine separated from the HC-toxin synthetase ${ }^{83)}$. Thus, in this filamentous fungus there is an epimerization domain converting L- to D-proline and a separate alanine racemase.

\section{Condensation Domains}

Accumulative sequence information from different peptide synthetases suggest that the so-called condensing domains ( $\mathrm{C}$ in Fig. 1) are responsible for the condensation of two activated amino acids on adjacent modules, i.e. it catalyzes the elongation reaction ${ }^{85)}$. No biochemical evidence is available, however, to support this hypothesis.

The condensation domain is about 450 amino acids in length. Its location in the multifunctional peptide synthetases follows two simple rules: i) It is always present between two adjacent activating units located on the same polypeptide, as it is the case with the ACV synthetase; ii) when the two consecutive activating domains are located on separate synthetases, the $\mathrm{C}$ domain is found at the $\mathrm{N}$ terminus of the amino acid-accepting synthetase ${ }^{61)}$.

Release of Enzyme Bound Peptides: Involvement of a

\section{Thioesterase}

With the exception of ACV synthetases and linear peptide synthetases, most other peptide synthetases do not release a peptide with a free terminal carboxyl group. Usually, the carboxyl group of the last amino acid that is bound to the enzyme as a thioester is transferred to the amino group of the same or a different peptide chain giving cyclic peptides (e.g. gramicidin S, tyrocidine, cyclosporin) or to a terminal or side-chain hydroxyl group (e.g. in the cyclodepsipeptides). In some linear peptides the terminal carboxyl group is released by aminolysis. In the biosynthesis of ACV the carboxyl group is released in the free form.

The carboxyl terminal region of the ACV synthetases of P. chrysogenum, A. nidulans, A. chrysogenum, $A$. lactamdurans (and also the known $C$-terminal region of the $S$. clavuligerus enzyme) shows a motif GXSXG homologous to the amino acid sequence of the active site of the oleoyl-ACP hydrolase (thioesterase I) of vertebrate fatty

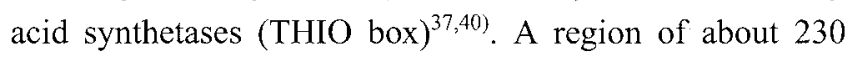
amino acids of the ACV synthetases extending from the THIO box to the $C$-terminus of the protein ( $\mathrm{R}$ in Fig. 1) shows high similarity to the $29 \mathrm{kDa}$ GrsT protein (a putative thioesterase) of the gramicidin $\mathrm{S}$ operon and to the $s r f n$-TE gene of the surfactin cluster supporting the hypothesis that the THIO region might be functional in the hydrolysis of the thioester bond of the enzyme-bound ACV tripeptide.

Recently the catalytic SHD of the active site of the
$142 \mathrm{kDa}$ Ent-F module of the enterobactin synthetase has been mutated in vitro. Results established that the THIO box of EntF is both a cyclotrimerizing lactone synthetase (forming the trilactone enterobactin) and an elongation catalyst for ester bond formation ${ }^{86)}$. The thioesterase domain of the ACV synthetase has also been modified ${ }^{87)}$. Unexpecteadly, the mutant ACV synthetase showed only a $50 \%$ reduction of the peptide formation rate, with the stereoisomer LLL-ACV as the dominating product. In summary, the THIO motif may be involved in the control of tripeptide epimerization by selection of the isomer to be released, and in the liberation of the final peptide.

\section{Future Outlook}

A long path has been walked since the initial discovery of the ACV tripeptide by ARNSTEIN and MORRIS ${ }^{3)}$ and LODER and ABRAHAM ${ }^{11,12)}$ to the modern concepts on amino acid activation, condensation and epimerization by the ACV synthetase. The modular nature of non-ribosomal peptide synthetases opens the way for engineering the multifunctional peptide synthetases ${ }^{88,89)}$. Efficient engineering of peptide synthases requires a better knowledge of the limits between domains and about the essential regions for catalytic functions of each domain ${ }^{90)}$. Novel hybrid tripeptide synthases will be constructed and some of them will lead to the formation of $\beta$-lactam and/or thiazolidine nucleus $^{91)}$ resulting in novel bioactive compounds.

\section{Acknowledgements}

This work was supported by grants of the European Union (BIO-CT94-2100 and QLK3-1999-00729). I acknowledge the help of P. Liras, S. Gutiérrez, F. Fierro and J. Casqueiro, and the excellent technical assistance of M. CORRALES.

\section{References}

1) ABraham, E. P.: Biosynthesis and enzymatic hydrolysis of penicillin and cephalosporins. University of Tokyo Press, Tokyo, 1974

2) Fawcett, P. A.; J. J. Usher, J. A. Huddleston, R. C. Bleaney, J. J. Nisbet \& E. P. Abraham: Synthesis of $\delta$ $(\alpha$-aminoadipyl)cysteinylvaline and its role in penicillin biosynthesis. Biochem. J. 157: 651 660, 1976

3) Arnstein, H. R. V. \& D. Morris: The structure of a peptide, containing $\alpha$-aminoadipic acid, cysteine and valine, present in the mycelium of Penicillium chrysogenum. Biochem. J. 76: 357 361, 1960

4) Abraham, E. P.: Enzymes involved in penicillin and cephalosporin formation. In Regulation of Secondary 
Metabolite Formation. Eds., KLeinkauf, H., H. von Döhren, H. Dornauer \& G. Nesemann, pp. 115 132, VCH, Weinheim, 1986

5) Demain, A. L.: Biosynthesis of $\beta$-lactam antibiotics. In Antibiotics Containing the $\beta$-Lactam Structure. Eds., Demain, A. L. \& N. A. Solomon, Springer Verlag, New York, 1983

6) Arnstein, H. R. V.; N. Artman, D. Morris \& E. J. Toms: Sulfur-containing amino acids and peptides in the mycelium of Penicillium chrysogenum. Biochem. J. 76: 353 357,1960

7) Chan, J. A.; F.-C. Huang \& C. J. SiH: The absolute configuration of the amino acids in $\delta$-( $\alpha$-aminoadipyl)cysteinyl-valine from Penicillium chrysogenum. Biochem. J. 15: 177 180, 1976

8) Neuss, N.; R. D. Miller, C. A. Affolder, W. Nakatsukosa, J. Mabe, L. L. Huckstepp, N. De La Higuera, A. H. Hunt, J. Occolowitz \& J. H. Gilham: High performance liquid chromatography (HPLC) of natural products. 3 . Isolation of new tripeptides from the fermentation broth of $P$. chrysogenum. Helv. Chim. Acta 63: $1119 \sim 1129,1980$

9) Avanzini, F. \& P. Valenti: Peptide presence constituted by $\alpha$-aminoadipic acid ( $\alpha$-AAA) and valine in $P$. chrysogenum fermentation broth. Abstracts 6th International Ferm Symp. London, Ontario, p. 18, 1980

10) Avanzini, F. \& S. Morelli: Amino acids and peptides in penicillin industrial fermentation broths by different $P$. chrysogenum strains. In Abstracts of the VII International Biotechnology Symposium, volume 2, pp. 368 369, New Delhi, India, 1984

11) Loder, P. B. \& E. P. Abraham: Isolation and nature of intracellular peptides from a cephalosporin C-producing Cephalosporium sp. Biochem. J. 123: 471 476, 1971

12) Loder, P. B. \& E. P. Abraham: Biosynthesis of peptides containing $\alpha$-aminoadipic acid and cysteine in extracts of a Cephalosporium sp. Biochem. J. 123: 477 482, 1971

13) Enriquez, L. A. \& M. A. Pisano: Isolation and nature of intracellular alpha-aminoadipic acid-containing peptides from Paecilomyces persicinus P-10. Antimicrob. Agents Chemother. 16: 392 -397, 1977

14) Adriaens, P; B. Meesschaerts, W. Wuyts, $H$. VANDERHAEghe \& H. EYSSEN: Presence of $\delta$-(L- $\alpha$ aminoadipyl)-L-cysteinyl-D-valine in fermentations of Penicillium chrysogenum. Antimicrob. Agents Chemother. 8: 638 642, 1975

15) Lopez-Nieto, M. J.; F. R. Ramos, J. M. Luengo \& J. F. MARTIN: Characterization of the biosynthesis in vivo of $\alpha$-aminoadipyl-cysteinyl-valine in Penicillium chrysogenum. Appl. Microbiol. Biotechnol. 22: $343 \sim 351,1985$

16) Banko, G.; S. Wolfe \& A. L. Demain: Cell-free synthesis of $\delta$-(L- $\alpha$-aminoadipyl)-L-cysteine, the first intermediate of penicillin and cephalosporin biosynthesis. Biochem. Biophys. Res. Commun. 137: $528 \sim 535,1986$

17) Martin, J. F.; T. D. Ingolia \& S. W. Queener: Molecular genetics of penicillin and cephalosporin antibiotic biosynthesis. In Molecular Industrial Mycology: Systems and Applications for Filamentous Fungi. Eds., LeONG S. A. \& R. M. BERKA, pp. 149 196, Marcel Dekker, New York, 1990
18) Zhang, J. \& A. L. Demain: Regulation of ACV synthetase in penicillin- and cephalosporin-producing microorganisms. Biotechnol. Adv. 9: 623 641, 1992

19) Kallow, W.; H. von Döhren \& H. Kleinkauf: Penicillin biosynthesis: energy requirement for tripeptide precursor formation by delta-(L-alpha-aminoadipyl)L-cysteinyl-D-valine synthetase from Acremonium chrysogenum. Biochemistry 37: 5947 -5952, 1998

20) Kennedy, J. \& G. Turner: delta-(L-alpha-aminoadipyl)L-cysteinyl-D-valine synthetase is a rate limiting enzyme for penicillin production in Aspergillus nidulans. Mol. Gen. Genet. 253: 189 197, 1996

21) Zhang, J. \& A. L. Demain: Purification from Cephalosporium acremonium of the initial enzyme unique to the biosynthesis of penicillins and cephalosporins. Biochem. Biophys. Res. Commun. 169:1145 1152, 1990

22) Baldwin, J. E.; J. W. Bird, R. A. Field, N. M. O'Callaghan, C. J. Schofield \& A. C. Willis: Isolation and partial characterization of $\mathrm{ACV}$ synthetase from Cephalosporium acremonium and Streptomyces clavuligerus: evidence for the presence of phosphopantothenate in ACV synthetase. J. Antibiotics 44: $241 \sim 248,1991$

23) Zhang, J. \& A. L. Demain: Purification of ACV synthetase from Streptomyces clavuligerus. Biotechnol. Lett. 12: 649 654, 1990

24) Van Liempt, H.; H. Von Döhren \& H. KleinkauF: $\delta$ ( $\mathrm{L}-\alpha$-aminoadipyl)-L-cysteinyl-D-valine synthetase from Aspergillus nidulans. J. Biol. Chem. 264: 3680 3684, 1989

25) Baldwin, J. E.; J. W. BiRd, R. A. Field, N. M. O'CAllaghan \& C. J. Schofield: Isolation and partial characterization of $\mathrm{ACV}$ synthetase from Cephalosporium acremonium and Streptomyces clavuligerus. J. Antibiotics 43:1055 1057, 1990

26) Jensen, S. E.; A. Wong, M. J. Rollins \& D. W. S. Westlake: Purification and partial characterization of $\delta$ ( $L-\alpha$-aminoadipyl)-L-cysteinyl-D-valine synthetase from Streptomyces clavuligerus. J. Bacteriol. 172: 7269 7271, 1990

27) Martín, J. F. \& P. Liras: Enzymes involved in penicillin, cephalosporin and cephamycin biosynthesis. In Advances in Biochemical Engineering and Biotechnology. $E d$., FieCHER, A., pp. 153 187, Springer Verlag, Berlin, Heidelberg, 1989

28) Aharonowitz, Y.; G. Cohen \& J. F. Martin: Penicillin and cephalosporin biosynthetic genes: structure, organization, regulation and evolution. Annu. Rev. Microbiol. 46: 461 496, 1992

29) Martin, J. F.: New aspects of genes and enzymes for beta-lactam antibiotic biosynthesis. Appl. Microbiol. Biotechnol. 50: 1 15, 1998

30) Adlington, R. L.; J. E. Baldwin, M. López-nieto, J. A. Murphy \& N. Patel: A study of the biosynthesis of the tripeptide $\delta$-(L- $\alpha$-aminoadipyl)-L-cyseinyl-D-valine in a $\beta$-lactam-negative mutant of Cephalosporium acremonium. Biochem. J. 213: 573 576, 1983

31) Banko, G.; A. L. Demain \& S. Wolfe: $\delta$-(L- $\alpha-$ aminoadipyl)-L-cysteinyl-D-valine synthetase (ACV synthetase): a multifunctional enzyme with broad substrate specificity for the synthesis of penicillin and cephalosporin precursors. J. Am. Chem. Soc. 109: 
$2858 \sim 2860,1987$

32) Theilgaard, H. B; K. N. Kristiansen, C. M. Henriksen \& J. Nielsen: Purification and characterization of delta-(L-alpha-aminoadipyl)-Lcysteinyl-D-valine synthetase from Penicillium chrysogenum. Biochem. J. 327: 185 191, 1997

33) Jensen, S. E.; D. W. S. Westlake \& S. Wolfe: Production of the penicillin precursor $\delta$-(L- $\alpha-$ aminoadipyl)-L-cysteinyl-D-valine (ACV) by cell-free extracts from Streptomyces clavuligerus. FEMS Microbiol. Lett. 49:213 218, 1988

34) Zhang, J.; S. Wolfe \& A. L. Demain: Biochemical studies of ACV synthetase activity from Streptomyces clavuligerus. Biochem. J. 283: 691 698, 1992

35) Baldwin, J. E.; C.-Y. Shiau, M. F. Byford \& C. J. SCHOFIELD: Substrate specificity of $\mathrm{L}-\delta-(\alpha-$ aminoadipoyl)-L-cysteinyl-D-valine synthetase from Cephalosporium acremonium: demonstration of the structure of several unnatural tripeptide products. Biochem. J. 301: 367 -372, 1994

36) Coque, J. J. R.; J. L. DE LA Fuente, P. Liras \& J. F. MARTIN: Overexpression of the Nocardia lactamdurans $\alpha$-aminoadipyl-cysteinyl-valine synthetase in Streptomyces lividans. The purified multienzyme uses cystathionine and 6-oxopiperidine 2-carboxylate as substrates for synthesis of the tripeptide. Eur. J. Biochem. 242: 264 270, 1996

37) Diez, B.; S. Gutierrez, J. L. Barredo, P. Van Solingen, L. H. M. VAn Der VoOrt \& J. F. Martin: The cluster of penicillin biosynthesis genes. Identification and characterization of the pcbAB gene encoding the $\alpha$ aminoadipyl-cysteinyl-valine synthetase and linkage to the $p c b \mathrm{C}$ and penDE genes. J. Biol. Chem. 265: $16358 \sim 16365,1990$

38) Smith, D. J.; M. K. R. Burnham, J. H. Bull, J. E. Hodgson, J. M. WARd, P. Browne, J. Brown, B. BARTON, A. J. EARL \& G. TURnER: $\beta$-Lactam antibiotic biosynthetic genes have been conserved in clusters in prokaryotes and eukaryotes. EMBO J. 9: 741 747, 1990

39) Cantoral, J. M.; S. Gutiérrez, F. Fierro, S. GilEsPinosa, H. VAN LIEMPT \& J. F. MARTÍN: Biochemical characterization and molecular genetics of nine mutants of Penicillium chrysogenum impaired in penicillin biosynthesis. J. Biol. Chem. 268: 737 744, 1993

40) Gutierrez, S.; B. Diez, E. Montenegro \& J. F. Martin: Characterization of the Cephalosporium acremonium pcbAB gene encoding $\alpha$-aminoadipyl-cysteinyl-valine synthetase, a large multidomain peptide synthetase: Linkage to the $p c b \mathrm{C}$ gene as a cluster of early cephalosporin biosynthetic genes and evidence of multiple functional domains. J. Bacteriol. 173: 2354 2365, 1991

41) Maccabe, A. P.; H. Van Liempt, H. Palissa, S. W. Unkles, M. B. R. Riach, E. Pfeifer, H. Von DöHren \& J. R. KINGHORN: $\delta$-(L- $\alpha$-Aminoadipyl)-L-cysteinyl-Dvaline synthetase from Aspergillus nidulans. Molecular characterization of the acvA gene encoding the first enzyme of the penicillin biosynthetic pathway. J. Biol. Chem. 266: 12646 12654, 1991

42) Montenegro, E.; F. Fierro, F. J. Fernandez, S. Gutierrez \& J. F. MARTIN: Resolution of chromosomes III and VI of Aspergillus nidulans by pulsed-field gel electrophoresis shows that the penicillin biosynthetic pathway genes $p c b \mathrm{AB}, p c b \mathrm{C}$, and $p e n \mathrm{DE}$ are clustered on chromosome VI (3.0 megabases). J. Bacteriol. 174: $7063 \sim 7067,1992$

43) Laich, F.; F. Fierro, R. E. Cardoza \& J. F. Martin: Organization of the gene cluster for biosynthesis of penicillin in Penicillium nalgiovense and antibiotic production in cured dry sausages. Appl. Environm. Microbiol. 65: 1236 1240, 1999

44) Coque, J. J. R.; J. F. Martin, J. G. Calzada \& P. LiRas: The cephamycin biosynthetic genes pcbAB, encoding a large multidomain peptide synthetase, and $p c b \mathrm{C}$ of Nocardia lactamdurans are clustered together in an organization different from the same genes in Acremonium chrysogenum and Penicillium chrysogenum. Mol. Microbiol. 5: 1125 1133, 1991

45) Barreiro, C.; A. Pisabarro \& J. F. Martin: Characterization of the ribosomal $r r n \mathrm{D}$ operon of the cephamycin-producer 'Nocardia lactamdurans' shows that this actinomycete belongs to the genus Amycolatopsis. System. Appl. Microbiol. 23: 15 24, 2000

46) Doran, J. L.; B. K. Leskiw, A. K. Petrich, D. W. S. Westlake \& S. E. Jensen: Production of Streptomyces clavuligerus isopenicillin $\mathrm{N}$ synthase in Escherichia coli using two-cistron expression system. J. Ind. Microbiol. 5: 197 206, 1990

47) Yu, H.; H. Y. E. Serpe, J. Romero, J. J. R. Coque, K. Maeda, M. Oelgeschläger, M. Hintermann, P. Liras, J. F. Martín, A. L. Demain \& J. Piret: Possible involvement of the lysine E-aminotransferase gene (lat) in the expression of the genes encoding $\mathrm{ACV}$ synthetase $(p c b \mathrm{AB})$ and isopenicillin $\mathrm{N}$ synthase $(p c b \mathrm{C})$ in Streptomyces clavuligerus. Microbiology 140: $3367 \sim 3377,1994$

48) Peñalva, M. A.; A. Moya, J. Dopazo D. Ramon: Sequences of isopenicillin $N$ synthetase gene suggest horizontal gene transfer from prokaryotes to eukaryotes. Proc. R. Soc. London Ser. B 241: 164 169, 1990

49) Liras, P; A. Rodriguez-Garcia \& J. F. MARTin: Evolution of the clusters of genes for $\beta$-lactam antibiotics: a model for evolutive combinatorial assembly of new $\beta$-lactams. Internatl. Microbiol. 1: $271 \sim 278$, 1998

50) Hoskins, J. A.; N. O'Callaghan, S. W. Queener, C. A. CANTWELL \& J. S. WOOD: Gene disruption of the $p c b A B$ gene encoding ACV synthetase in Cephalosporium acremonium. Curr. Genet. 18: 523 530, 1990

51) Fierro, F.; E. Montenegro, S. Gutierrez \& J. F. MARTIN: Mutants blocked in penicillin biosynthesis show a deletion of the entire penicillin gene cluster at a specific site within a conserved hexanucleotide sequence. Appl. Microbiol. Biotechnol. 44: 597 604, 1996

52) Fierro, F.; J. L. Barredo, B. Diez, S. Gutiérrez, F. J. FERNÁNDEZ \& J. F. MARTín: The penicillin gene cluster is amplified in tandem repeats linked by conserved hexanucleotide sequences. Proc. Natl. Acad. Sci. USA 92: $6200 \sim 6204,1995$

53) Kleinkauf, H. \& H. von Döhren: Nonribosomal biosynthesis of peptide antibiotics. Eur. J. Biochem. 19: $1 \sim 15,1990$

54) Martín, J. F.: Nonribosomal peptides. Ed., Meyers R. A., pp. 207 217, Encyclopedia of Molecular Biology, 
VCH, Germany, 1996

55) Kleinkauf, H. \& H. VON DÖhren: A nonribosomal system of peptide biosynthesis. Eur. J. Biochem. 192: $1 \sim 15,1996$

56) Von Döhren, H.; U. Keller, J. Vater \& R. Zocher: Multifunctional peptide synthetases. Chem. Rev. 97: 2675 2705, 1997

57) Casqueiro, J.; S. Gutiérrez, o. Bañuelos, F. Fierro, J. VELASCO \& J. F. MARTIN: Characterization of the lys2 gene of Penicillium chrysogenum encoding $\alpha$ aminoadipic acid reductase. Mol. Gen. Genet. 259: 549 556, 1998

58) Hijarrubia, M. J.; J. F. Aparicio \& J. F. Martín: Characterization of the lys 2 gene of Acremonium chrysogenum encoding a functional (-aminoadipate activating and reducing enzyme. Mol. Gen. Genet. (in press), 2000

59) Criado, L. M.; J. F. Martín \& J. A. Gil: The $p a b$ gene of Streptomyces griseus, encoding p-aminobenzoic acid synthase, is located between genes possibly involved in candicidin biosynthesis. Gene 126: 135 139, 1993

60) Turgay, K.; M. Krause \& M. A. Marahiel: Four homologous domains in the primary structure of GrsB are related to domains in a superfamily of adenylate forming enzymes. Mol. Microbiol. 6: 529 546, 1992

61) Marahiel, M. A.; T. Stachelhaus \& H. D. Mootz: Modular peptide synthetases involved in non-ribosomal peptide synthesis. Chem. Rev. 97: 2651 2673, 1997

62) Lambalot, R. H.; A. M. Gehring, R. S. Flugel, P. Zuber, M. Lacelle, M. A. Marahiel, R. Reid, C. Khosla \& C. T. WaLSH: A new enzyme superfamily-the phosphopantetheinyl transferases. Chem. Biol. 3: 923 936, 1996

63) KleinKauf, H. \& H. von Döhren: Linking peptide and polyketide biosynthesis. J. Antibiotics 48: 563 567, 1995

64) Haese, A.; M. Schubert, M. Herrmann \& R. Zocher: Molecular characterization of the enniantin synthetase gene encoding a multifunctional enzyme catalysing $N$ methyldepsipeptide formation in Fusarium scirpi. Mol. Microbiol. 7: 905 914, 1993

65) Weber, G.; K. Schörgendorfer, E. SChnetderSCHERzER \& E. LeITNER: The peptide synthetase catalyzing cyclosporine production in Tolypocladium niveum is encoded by a giant 45.8 kilobase open reading frame. Curr. Genet. 26: 120 125, 1994

66) LÜCK-KLATTE, B.: Untersuchungen zur biosynthese von lysobactin in Lysobacter sp. S. clavuligerus 14,067 und charakterisierung von beteiligten multienzymen. Ph.D. Thesis, TU, Berlin, 1994

67) Shiau, C.-Y.; J. E. Baldwin, M. F. Byford \& C. J. SCHOFIELD: $\delta$-L- $(\alpha$-Aminoadipoyl $)$-L-cysteinyl-D-valine synthetase: isolation of L-cysteinyl-D-valine, a 'shunt' product, and implications for the order of peptide bond formation. FEBS Lett. 373: 303 306, 1995a

68) Shiau, C.-Y.; J. E. Baldwin, M. F. Byford, W. J. Sobey $\&$ C. J. SCHOFIELD: $\delta$-L-( $\alpha$-Aminoadipoyl)-L-cysteinyl-Dvaline synthetase: the order of peptide bond formation and timing of the epimerisation reaction. FEBS Lett. 358: $35 \sim 40,1995 \mathrm{~b}$

69) Shiau, C. Y.; M. F. Byford, R. T. Aplin, J. E. Baldwin \& C. J. SCHOfIELD: L- $\delta$-( $\alpha$-Aminoadipoyl)-L-cysteinyl-Dvaline synthetase: thioesterification of valine is not obligatory for peptide bond formation. Biochemistry 36 : 8798 8806, 1997

70) Aharonowitz, Y; J. Bergmeyer, J. M. Cantoral, G. Cohen, A. L. Demain, U. Fink, J. Kinghorn, H. Kleinkauf, A. Maccabe, H. Palissa, E. Pfeifer, T. SCHWECKE, $H$. VAN LIEMPT, H. VON DÖHREN, S. WOLFE \& J. ZHANG: $\delta$-(L- $\alpha$-Aminoadipyl)-L-cysteinyl-D-valine synthetase, the multienzyme integrating the four primary reactions in $\beta$-lactam biosynthesis, as a model peptide synthetase. Biotechnology 11: 807 810, 1993

71) Stachelhaus, T. \& M. A. Marahiel: Modular structure of genes encoding multifunctional peptide synthetase required for non-ribosomal peptide synthesis. FEMS Microbiol. Lett. 125: 3 14, 1995

72) Stachelhaus, T.; H. D. Mootz, V. Bergendahl \& M. A. MARAHIEL: Peptide bond formation in nonribosomal peptide biosynthesis. Catalytic role of the condensation domain. J. Biol. Chem. 273: 22773 22781, 1998

73) Schneider, A.; T. Stachelhaus \& M. A. Marahiel: Targeted alteration of the substrate specificity of peptide synthetases by rational module swapping. Mol. Gen. Genet. 257: 308 318, 1998

74) Challis, G. L.; J. Ravel \& C. A. Townsend: Predictive, structure-based model of amino acid recognition by nonribosomal peptide synthetase adenylation domains. Chem. Biol. 7: 21 1 224, 2000

75) Schatelhaus, T. \& M. A. Marahiel: Modular structure of peptide synthetases revealed by dissection of the multifunctional enzyme GrsA. J. Biol. Chem. 270: $6163 \sim 6169,1995$

76) Contl, E.; T. Stachelhaus, M. A. Marahiel \& P. BRICK: Structural basis for the activation of phenylalanine in the non-ribosomal biosynthesis of gramicidin S. EMBO J. 16: 4174 4183, 1997

77) Schlumbohm, W.; T. Stein, C. Ullrich, J. Vater, M. Krause, M. A. Marahiel, V. Kruft \& B. WittmannLIEBOLD: An active serine is involved in covalent substrate amino acid binding at each reaction center of gramicidin S synthetase. J. Biol. Chem. 266: 23135 23141, 1991

78) Ishinara, H.; Y. Endo, S. Abe \& K. Shimura: The presence of $4^{\prime}$-phosphopantetheine in the bacitracin synthetase. FEBS Lett. 50: 43 46, 1975

79) Martin, J. F. \& S. Gutiérrez: Molecular genetics of fungal secondary metabolites. Eds., Kinghorn, J. R. \& G. Turner, pp. 214 252, Applied Molecular of Filamentous Fungi, Blackie and Son, Ltd., Glasgow, 1992

80) Martin, J. F.; S. Gutierrez \& J. F. Aparicio: Secondary metabolites. Ed., LEDERBERG, J., Enzyclopedia of Microbiology, Vol. 4, Academic Press (in press), 2000

81) Fuma, S.; Y. Fujishima, N. Corbell, C. D'souza, M. M. NAKANo, P. ZubER \& K. YAmane: Nucleotide sequence of $5^{\prime}$ portion of srfA that contains the region required for competence establishment in Bacillus subtilis. Nucl. Acids Res. 21: 93 97, 1993

82) Stachelhaus, T. \& M. A. Marahiel: Modular structure of genes encoding multifunctional peptide synthetases required for non-ribosomal peptide synthesis. FEMS Microbiol. Lett. 125: 3 14, 1995

83) Cheng, Y.-Q. \& J. D. WALton: A eukaryotic alanine racemase gene involved in cyclic peptide biosynthesis. J. Biol. Chem. 275: 4906 4911, 2000 
84) Hoffmann, K.; E. Schneider-Scherzer, H. Kleinkauf \& R. ZOCHER: Purification and characterization of eucaryotic alanine racemase acting as key enzyme in cyclosporin "biosynthesis. J. Biol. Chem. 269: $12710 \sim 12714,1994$

85) De Crécy-Lagard, V.; P. Marlière \& W. SAurin: Multienzyme non ribosomal peptide biosynthesis: identification of the functional domains catalysing peptide elongation and epimerisation. C.r. Acad. Sci. III 318: 927 -936, 1995

86) Show-Reid, C. A.; N. L. Kelleher, H. C. Losey, A. M. Gehring, C. Berg \& C. T. Walsh: Assembly line enzymology by multimodular nonribosomal peptide synthetases: the thioesterase domain of E. coli EntF catalyzes both elongation and cyclolactonization. Chem. Biol. 6: 385 400, 1999

87) Kallow, W.; J. Kennedy, B. Arezi, G. Turner \& H. VON DÖHREN: Thioesterase domain of delta-(1-alphaaminoadipyl)-1-cysteinyl-d-valine synthetase: alteration of stereospecificity by site-directed mutagenesis. J. Mol. Biol. 297: 395 408, 2000

88) Symmmank, H.; W. Saenger \& F. Bernhard: Analysis of engineered multifunctional peptide synthetases. Enzymatic characterization of surfactin synthetase domains in hybrid bimodular systems. J. Biol. Chem. 274: $21581 \sim 21588,1999$

89) Mootz, H. D. \& M. A. Marahiel: Design and application of multimodular peptide synthetases. Curr. Opin. Biotechnol. 10: 341 348, 1999

90) Stachelhaus, T.; A. Schneider \& M. A. Marahiel: Rational design of peptide antibiotics by targeted replacement of bacterial and fungal domains. Science 269: $69 \sim 72,1995$

91) Gehring, A. M.; I. Mori, R. D. Perry \& C. T. Walsh: The nonribosomal peptide synthetase HMWP2 forms a thiazoline ring during biogenesis of yersiniabactin, an iron-chelating virulence factor of Yersinia pestis. Biochemistry 37: 11637 11650, 1998 